\title{
Heat of Formation of Titanium Trichloride
}

\author{
Walter H. Johnson, Alexis A. Gilliland, and Edward J. Prosen
}

(August 2, 1960)

\begin{abstract}
A calorimetric comparison of the heat of hydrolysis of $\mathrm{TiCl}_{4}(\mathrm{liq})$ with the heat of oxidation and hydrolysis of $\mathrm{TiCl}_{3}(\mathrm{c})$ has been made. The following value is reported for the combination of these data according to the process:

$$
\begin{gathered}
\mathrm{TiCl}_{3}(\mathrm{c})+1 / 2 \mathrm{I}_{2}(\mathrm{c})+\mathrm{HCl}(\mathrm{g}) \rightarrow \mathrm{TiCl}_{4}(\mathrm{liq})+\mathrm{HI}(\mathrm{g}), \\
\Delta \mathrm{H}^{\circ}\left(25^{\circ} \mathrm{C}\right)=8.37 \pm 0.30 \mathrm{kcal} / \mathrm{mole} .
\end{gathered}
$$

A combination of this value with $-192.3 \pm 0.7 \mathrm{kcal} / \mathrm{mole}$ for the heat of formation of $\mathrm{TiCl}_{4}$ (liq) and with the standard heats of formation of $\mathrm{HCl}(\mathrm{g})$ and $\mathrm{HI}(\mathrm{g})$ gives for $\mathrm{TiCl}_{3}(\mathrm{c})$, $\Delta \mathrm{Hf}^{\circ}\left(25^{\circ} \mathrm{C}\right)=-172.4 \pm 0.8 \mathrm{kcal} / \mathrm{mole}$.
\end{abstract}

\section{Introduction}

Several independent determinations of the heat of formation of titanium trichloride have been reported during the past few years $[1,2,3,4,5,6]{ }^{1} \quad$ The only values previously available were those estimated by Brewer, Bromley, Gilles, and Lofgren [7] and by Kubaschewski and Evans [8], which are now generally known to be low. The difficulties encountered in the purification of titanium trichloride and its reactivity toward oxygen and moisture have no doubt contributed to the scarcity of experimental data.

We conducted a number of experiments on the reaction between crystalline $\mathrm{TiCl}_{3}$ and gaseous chlorine in a calorimetric vessel originally designed for measurement of the heat of formation of boron trichloride [9]. Although $\mathrm{TiCl}_{3}(\mathbf{c})$ is readily converted to $\mathrm{TiCl}_{4}(\mathrm{~g})$ by the action of chlorine at about $300{ }^{\circ} \mathrm{C}$, a portion of the finely divided sample was carried away by the gas stream. The insertion of a glass wool plug tended to reduce the transfer of $\mathrm{TiCl}_{3}$, but the presence of adsorbed moisture introduced significant errors in the determination of the quantity of reaction.

We therefore decided to use a solution calorimeter to make a comparison between the heats of formation of $\mathrm{TiCl}_{3}$ (c) and $\mathrm{TiCl}_{4}(\mathrm{liq})$. When $\mathrm{TiCl}_{3}(\mathrm{c})$ is added to aqueous acid containing an oxidizing agent, the titanium is converted to the tetravalent state; the resulting solution may be reproduced by adding $\mathrm{TiCl}_{4}$ to an acid solution which contains the reduced form of the oxidizing agent. The difference between the heats of formation of $\mathrm{TiCl}_{4}$ and $\mathrm{TiCl}_{3}$ may be determined from a combination of the heat of oxidation and hydrolysis of $\mathrm{TiCl}_{3}$ with the heat of hydrolysis of $\mathrm{TiCl}_{4}$ and with certain auxiliary data. This method is similar to that employed by Clifton and MacWood [1], except that the experiments were performed at $30^{\circ} \mathrm{C}$ instead of $0{ }^{\circ} \mathrm{C}$ and iodine was used as the oxidizing agent instead of $\mathrm{FeCl}_{3}$.

${ }^{1}$ Figures in trackets indicate the literat!re references at the end of this paper.

\section{Source and Purity of Materials}

The $\mathrm{TiCl}_{4}$ and $\mathrm{TiCl}_{3}$ were prepared by the Inorganic Chemistry Section of the Chemistry Division. The purity of the $\mathrm{TiCl}_{4}$ was determined to be 99.99 mole percent by freezing point determinations made in the Pure Substances Section of the Chemistry Division. This material was the same as that used previously for the determination of the heat of formation of $\mathrm{TiI}_{4}[9]$.

The purity of the $\mathrm{TiCl}_{3}$ was determined by the Inorganic Chemistry Section to be greater than 99.8 percent. Analyses of the solutions obtained after bydrolysis indicated the purity to be $100 \pm 0.2$ percent.

The iodine, potassium iodide, and hydrochloric acid were reagent-grade materials used with no further purification. The hydriodic acid was redistilled and the constant-boiling fraction collected under a nitrogen atmosphere.

\section{Apparatus and Procedure}

The apparatus was the same as that used for the determination of the heat of formation of $\mathrm{TiI}_{4}$ [9], except for minor changes. Capillary inlet and exit tubes were inserted through the calorimeter head to permit removal of oxygen by flushing with nitrogen. Calorimeter temperatures were measured by means of a platinum resistance thermometer. The thermometric system, the apparatus for measurement of electrical energy, and the calorimetric procedure have been described in previous reports [11, 12].

\subsection{Hydrolysis of $\mathrm{TiCl}_{4}$ (liq)}

Samples, approximately 0.01 mole each, of the $\mathrm{TiCl}_{4}$ were transferred into thin-walled, spherical Pyrex bulbs and sealed in vacuum. The calorimetric solution consisted of 0.01 mole KI, 0.02 mole $\mathrm{I}_{2}, 0.40$ mole $\mathrm{HCl}, 0.01$ mole $\mathrm{HI}$, and 25.33 moles water. The iodine and KI were dissolved in a small quantity of water before adding the other 
materials; the HI was taken from a constant-boiling solution and the $\mathrm{HCl}$ from a prepared $4 \mathrm{~N}$ solution. The remainder of the water was added to bring the total weight up to the previously calculated value. The calorimeter was then assembled, placed in the constant-temperature calorimeter jacket, the stirrer connected, and oxygen removed by flushing with nitrogen. The inlet and exit tubes were then closed, leaving a slight positive pressure of about $1 \mathrm{~mm}$ above atmospheric pressure in the calorimeter.

Calorimeter temperatures were noted at 2-minute intervals during the initial rating-period, after which the sample bulb was crushed and temperatures measured at 1-minute intervals until thermal equilibrium was reestablished. Temperatures were then noted at 2-minute intervals during a final ratingperiod.

The rate of hydrolysis was quite rapid, the hydrolysis being essentially complete within one minute. In a few cases some of the calorimetric solution was splashed upon the upper walls of the vessel; in such cases the experiment was discarded. The reaction produced no noticeable difference in the color of the solution.

The calorimeter was calibrated in the same manner, except that an empty bulb was used and the temperature rise was derived from a carefully measured quantity of electrical energy introduced into the system.

\subsection{Hydrolysis of $\mathrm{TiCl}_{3}(\mathrm{~s})$}

Samples, approximately 0.01 mole each, of the finely divided $\mathrm{TiCl}_{3}$ were transferred into glass bulbs in a dry-box under an atmosphere of nitrogen. The bulbs were capped while in the box, then removed and sealed.

The calorimetric solution was the same as that used for the experiments with $\mathrm{TiCl}_{4}$, except that the $\mathrm{HI}$ was omitted and the quantities of iodine and $\mathrm{HCl}$ were increased to 0.025 and 0.41 mole respectively. The calorimetric procedure was the same as that described for the $\mathrm{TiCl}_{4}$ experiments.

The rate of hydrolysis was quite rapid at first, but quickly slowed down; the hydrolysis was not complete after $1 \frac{1}{2} \mathrm{hrs}$ at $25^{\circ} \mathrm{C}$. We found it necessary to raise the calorimeter temperature to $30{ }^{\circ} \mathrm{C}$ in order to obtain complete hydrolysis within one hour. The resulting solutions developed some turbidity after standing in air for a few hours. In a few cases the solutions were stored in completely filled and stoppered amber bottles; in these cases no turbidity appeared even after several days.

The system was calibrated with electrical energy, at 25 and at $30^{\circ} \mathrm{C}$, using both the initial and final solutions in order to obtain $\triangle C p$ for the actual calorimetric process. The effective heat capacity of the empty calorimeter was determined by substituting a known weight of distilled water for the calorimetric solution.

\subsection{Heat of Solution of Iodine}

The iodine samples, approximately 0.005 mole each, were sealed into glass bulbs. The calorimetric solution was the same as used for $\mathrm{TiCl}_{3}$ experiments, except that only 0.02 mole of iodine was used. Because the solution of iodine resulted in a relatively small drop in the calorimeter temperature, it was possible to calibrate the actual system immediately prior to the measurement of the heat of solution and it was not necessary to duplicate the system exactly for replicate experiments.

\subsection{Heat of Dilution of Hydrochloric Acid}

A solution of hydrochloric acid containing 13.5 moles of water per mole of $\mathrm{HCl}$ was prepared. Samples of this solution, each containing approximately 0.01 mole of $\mathrm{HCl}$, were sealed into glass bulbs. The calorimetric solution consisted of 0.10 mole KI, 0.02 mole $\mathrm{I}_{2}, 0.40$ mole $\mathrm{HCl}$, and 25.195 moles of water. Since the increase in the calorimeter temperature was small, it was possible to calibrate the actual system before each experiment as described above.

\section{Data and Calculations}

Values from the 1955 table of International Atomic Weights [13] were used in all calculations. Except where specified to the contrary, the final temperature and pressure were $25^{\circ} \mathrm{C}$ and 1 atmosphere. One thermochemical calorie is taken as equivalent to 4.1840 joules.

The results of the calibration experiments on the $\mathrm{TiCl}_{4}$ system are given in table $1 . \quad E$ is the electrical

TABLE 1. Results of the calibration experiments on the $\mathrm{TiCl}_{4}$ system

\begin{tabular}{|c|c|c|c|}
\hline $\begin{array}{l}\text { Experi- } \\
\text { ment }\end{array}$ & $E$ & $\Delta R c$ & $E_{s}$ \\
\hline $\begin{array}{l}1 \\
2 \\
3 \\
4 \\
5 \\
6\end{array}$ & $\begin{array}{l}j \\
1939.62 \\
1937.46 \\
1936.64 \\
1934.99 \\
1936.37 \\
1931.84\end{array}$ & $\begin{array}{l}\text { ohm } \\
0.090254 \\
.090022 \\
.090053 \\
.090001 \\
.090235 \\
.090000\end{array}$ & $\begin{aligned} & j / \mathrm{ohm} \\
& 21491 \\
& 21522 \\
& 21506 \\
& 21500 \\
& 21459 \\
& 21465\end{aligned}$ \\
\hline \multicolumn{3}{|c|}{$\begin{array}{l}\text { Mean } \\
\text { Standard deviation of the mean }\end{array}$} & $\begin{array}{r}21490 \\
\pm 10\end{array}$ \\
\hline
\end{tabular}

energy introduced into the system as measured by a method described previously [11, 12]. $\Delta R c$ is the temperature rise of the calorimetric system as measured with a particular platinum resistance thermometer and bridge, corrected by a method described previously [14]. The energy equivalent of the system $E_{s}$, is the ratio of the quantity of electrical energy to the resulting rise in temperature:

$$
E_{s}=\frac{E}{\Delta R c} .
$$

The results of the experiments on the hydrolysis of $\mathrm{TiCl}_{4}$ ara given in table 2 , where $\Delta e$ is the deviation in the energy equivalent of the actual system from that of the calibrated system, $\Delta R c$ is the temperature 
The heats of solution of $\mathrm{HCl}$ (gas) and of $\mathrm{HI}$ (gas) have been calculated from available data [15] for the following processes:

$$
\begin{aligned}
& \mathrm{HCl} \text { (gas) }+13.5 \mathrm{H}_{2} \mathrm{O}(\text { liq }) \rightarrow \\
& {\left[\mathrm{HCl}+13.5 \mathrm{H}_{2} \mathrm{O}\right] \text { (soln) ; }}
\end{aligned}
$$

$\Delta \mathrm{H}\left(25^{\circ} \mathrm{C}\right)=-16.77 \pm 0.01 \mathrm{kcal} / \mathrm{mole}$,

$$
\begin{gathered}
\mathrm{HI}(\text { gas })+\left[10 \mathrm{KI}+2 \mathrm{I}_{2}+40 \mathrm{HCl}+2533 \mathrm{H}_{2} \mathrm{O}\right](\text { soln }) \rightarrow \\
{\left[10 \mathrm{KI}+2 \mathrm{I}_{2}+\mathrm{HI}+40 \mathrm{HCl}+2533 \mathrm{H}_{2} \mathrm{O}\right](\text { soln }) ;}
\end{gathered}
$$

$\Delta \mathrm{H}\left(25^{\circ} \mathrm{C}\right)=-19.51 \pm 0.10 \mathrm{kcal} / \mathrm{mole}$.

The heat involved in diluting the $\mathrm{KI}-\mathrm{I}_{2}-\mathrm{HCl}$ solution by approximately 0.5 percent has been calculated to be negligible within the precision of these experiments. For simplification of calculations, however, the following process has been included:

$$
\begin{array}{r}
13.5 \mathrm{H}_{2} \mathrm{O}(\mathrm{liq})+\left[10 \mathrm{KI}+2 \mathrm{I}_{2}+40 \mathrm{HCl}\right. \\
\left.+2519.5 \mathrm{H}_{2} \mathrm{O}\right](\mathrm{soln})
\end{array}
$$$$
\rightarrow\left[10 \mathrm{KI}+2 \mathrm{I}_{2}+40 \mathrm{HCl}+2533 \mathrm{H}_{2} \mathrm{O}\right](\text { soln }) ;
$$

$$
\Delta \mathrm{H}\left(25^{\circ} \mathrm{C}\right)=0.00 \pm 0.01 \mathrm{kcal} / \mathrm{mole} .
$$

We may subtract eqs (1), (6), and (7) from the sum of eqs (2), (3), (4), and (5) to obtain the following theoretical process:

$$
\underset{\mathrm{TiCl}_{3}(\mathrm{c})+\frac{1}{2} \mathrm{I}_{2}(\mathrm{c})+\mathrm{HCl}(\text { gas })}{\rightarrow} \mathrm{TiCl}_{4}(\mathrm{liq})+\mathrm{HI}(\text { gas }) ;
$$

$\Delta \mathrm{H}^{\circ}\left(25^{\circ} \mathrm{C}\right)=8.37 \pm 0.30 \mathrm{kcal} / \mathrm{mole}$.

The change in enthalpy for eq (8) may be combined with $-22.063 \pm 0.002$ and $6.20 \pm 0.10 \mathrm{kcal} / \mathrm{mole}$, the standard heats of formation of $\mathrm{HCl}$ (gas) and $\mathrm{HI}$ (gas) [15] respectively, to give:

$$
\mathrm{TiCl}_{3}(\mathrm{c})+\frac{1}{2} \mathrm{Cl}_{2}(\text { gas }) \rightarrow \mathrm{TiCl}_{4}(\mathrm{liq}) ;
$$

$\Delta \mathrm{H}^{\circ}\left(25^{\circ} \mathrm{C}\right)=-19.89 \pm 0.32 \mathrm{kcal} /$ mole

By taking $-192.3 \pm 0.7 \mathrm{kcal} / \mathrm{mole}$ for the heat of formation of $\mathrm{TiCl}_{4}(\mathrm{liq})[16],{ }^{2}$ we obtain:

$$
\mathrm{TiCl}_{3}(\mathrm{c}), \Delta \mathrm{Hf}^{\circ}\left(25^{\circ} \mathrm{C}\right)=-172.4 \pm 0.8 \mathrm{kcal} / \mathrm{mole} .
$$

The results obtained from the experiments on the direct chlorination gave $-19.9 \pm 1.3 \mathrm{kcal} / \mathrm{mole}$ for the process corresponding to eq (9).

The uncertainties assigned to the values given in this paper are over-all uncertainties obtained by combining twice the standard deviation of the mean for the calibration and reaction experiments with reasonable estimates of all other known sources of error.

\footnotetext{
2 The heat of vaporization of $\mathrm{TiCl}_{4}$ (liq) has been taken as $9.9 \pm 0.2 \mathrm{kcal} / \mathrm{mole}$ from the calorimetric data of Schaffer, Breil, and Pfeffer [2].
}

\section{Discussion}

The value obtained in this investigation is essentially the same as that obtained by Clifton and MacWood [1] from measurements of the energies evolved when $\mathrm{TiCl}_{3}(\mathrm{c})$ and $\mathrm{TiCl}_{4}(\mathrm{liq})$ were dissolved in an aqueous solution of $\mathrm{HCl}$ and $\mathrm{FeCl}_{3}$.

Schaffer, Breil, and Pfeffer [2] measured the heat of chlorination of $\mathrm{TiCl}_{3}$ at $57^{\circ} \mathrm{C}$ and obtained -20.3 $\mathrm{kcal} /$ mole for the process corresponding to eq (9). They also measured the heat of reduction of $\mathrm{TiCl}_{4}$ at $153{ }^{\circ} \mathrm{C}$, with mercury as the reducing agent, and obtained $-19.8 \mathrm{kcal} / \mathrm{mole}$ for eq (9). The values which they reported for the heat of formation of $\mathrm{TiCl}_{3}$, however, were based upon the value calculated by Bichowsky and Rossini [17] for the heat of formation of $\mathrm{TiCl}_{4}(\mathrm{liq})$, which has since been shown to be low. If we combine the data obtained by Schaffer, Breil, and Pfeffer with $-192.3 \pm 0.7 \mathrm{kcal} / \mathrm{mole}$ for the heat of formation of $\mathrm{TiCl}_{4}$ (liq), we obtain -172.0 and $-172.5 \mathrm{kcal} / \mathrm{mole}$ for the heats of formation of $\mathrm{TiCl}_{3}$ (c) obtained by the chlorination and reduction processes, respectively.

Krieve and Mason [3] studied the equilibrium:

$$
\left.\mathrm{TiCl}_{3}(\mathrm{c})+\mathrm{HCl}(\text { gas })=\mathrm{TiCl}_{4}(\text { gas })+\frac{1}{2} \mathrm{H}_{2} \text { (gas }\right),
$$

and obtained $\Delta \mathrm{H}_{690}=10.4 \mathrm{kcal} / \mathrm{mole}$. They estimated the $\Delta C p$ of the process to be $-6 \mathrm{cal} / \mathrm{deg}$ mole, used Kelley's value of $9.6 \mathrm{kcal} / \mathrm{mole}$ [18] for the heat of vaporization of $\mathrm{TiCl}_{4}$ (liq) [2], and obtained - 19.0 $\mathrm{kcal} / \mathrm{mole}$ for eq (9). We have corrected their data by the use of $9.9 \mathrm{kcal} / \mathrm{mole}$ for the heat of vaporization of liquid $\mathrm{TiCl}_{4}$ [2] and have obtained $-19.3 \mathrm{kcal} / \mathrm{mole}$ for the process corresponding to eq (9). Combination of this value with -192.3 $\mathrm{kcal} / \mathrm{mole}$ for the heat of formation of $\mathrm{TiCl}_{4}(\mathrm{liq})$, gives $-173.0 \mathrm{kcal} / \mathrm{mole}$ for the heat of formation of $\mathrm{TiCl}_{3}(\mathrm{c})$.

Krieve, Vango, and Mason [4] reacted Ti(c), $\mathrm{TiCl}_{2}(\mathrm{c})$, and $\mathrm{TiCl}_{3}(\mathrm{c})$ with chlorine under pressure in a nickel-bomb calorimeter to form $\mathrm{TiCl}_{4}(\mathrm{liq})$. They obtained -190.0 and $-20.9 \mathrm{kcal} / \mathrm{mole}$ for the heats of chlorination of $\mathrm{Ti}(\mathrm{c})$ and $\mathrm{TiCl}_{3}(\mathrm{c})$, respectively, and reported $-169.1 \mathrm{kcal} / \mathrm{mole}$ for the heat of formation of $\mathrm{TiCl}_{3}(\mathrm{c})$. If we take their value for the heat of chlorination of $\mathrm{TiCl}_{3}(\mathrm{c})$ and use our value for the heat of formation of $\mathrm{TiCl}_{4}(\mathrm{liq})$, we obtain $-171.4 \mathrm{kcal} / \mathrm{mole}$ for the heat of formation of $\mathrm{TiCl}_{3}(\mathrm{c})$.

Skinner and Ruehrwein [5] measured the heats of solution of $\mathrm{Ti}(\mathrm{c})$ and $\mathrm{TiCl}_{3}$ (c) in aqueous hydrofluroic acid. They obtained $-170.0 \mathrm{kcal} / \mathrm{mole}$ for the heat of formation of $\mathrm{TiCl}_{3}(\mathrm{c})$.

Altman, Farber, and Mason [6] have reported values of -169.4 and $-171.0 \mathrm{kcal} / \mathrm{mole}$ for the heat of formation of $\mathrm{TiCl}_{3}(\mathrm{c})$, based upon disproportionation and sublimation studies by Farber and Darnell $[19,20]$.

A summary of the results obtained by the various investigators is given in table 7. An examination of the results in this table indicates substantial 
agreement on the difference between the heats of formation of $\mathrm{TiCl}_{3}(\mathrm{c})$ and $\mathrm{TiCl}_{4}(\mathrm{liq})$.

TABLE 7. Heat of formation of $\mathrm{TiCl}_{3}$ reported by the various investigators, $\mathrm{kcal} / \mathrm{mole}$ at $25{ }^{\circ} \mathrm{C}$

\begin{tabular}{c|c|c}
\hline \hline \multirow{2}{*}{$\Delta \mathrm{Hf}_{\mathrm{TiCl}_{3}(\mathrm{~s})-\Delta \mathrm{Hf} \mathrm{TiCl}_{4}(\mathrm{liq})}$} & $-\Delta \mathrm{Hf}_{\mathrm{TiCl}_{3}(\mathrm{~s})}$ & Reference \\
\cline { 1 - 1 } 19.9 & 172.4 & 1 \\
20.3 & 172.0 & 2 \\
19.8 & 172.5 & 2 \\
19.3 & 173.0 & 3 \\
20.9 & 169.1 & 4 \\
& 171.4 & 4 \\
& 170.0 & 5 \\
& 169.4 & 6 \\
$19.9 \pm 0.3$ & 171.0 & 6 \\
& $172.4 \pm 0.8$ & This investigation. \\
\hline
\end{tabular}

\section{References}

[1] D. G. Clifton and G. E. MacWood, J. Phys. Chem. 60, 309 (1956).

[2] H. Schaffer, G. Breil, and G. Pfeffer, Z. anorg. u. allgem. Chem. 276, 325 (1954).

[3] W. F. Krieve and D. M. Mason, J. Chem. Phys. 25, 524 (1956).

[4] W. F. Krieve, S. P. Vango, and D. M. Mason, J. Chem. Phys. 25, 519 (1956).

[5] G. B. Skinner and R. A. Ruehrwein, J. Phys. Chem. 59, 113 (1955).

[6] D. Altman, M. Farber, and D. M. Mason, J. Chem. Phys. 25, 531 (1956).
[7] L. Brewer, L. A. Bromley, P. W. Gilles, and N. L. Lofgren, Paper No. 6 in L. L. Quill, Chemistry and metallurgy of miscellaneous materials, thermodynamics, National Nuclear Energy Series IV-19B, (MeGraw-Hill Book Company, Inc., New York, N.Y., 1950).

[8] O. Kubaschewski and E. LL. Evans, Metallurgical thermochemistry, Vol. I (Academic Press Inc., New York 10, N. Y., 1951).

[9] W. H. Johnson, R. G. Miller, and E. J. Prosen, J. Research NBS 62, 213 (1959) RP2956.

[10] W. H. Johnson, A. A. Gilliland, and E. J. Prosen, J. Research NBS 63A, 161, (1959).

[11] E. J. Prosen, F. W. Maron, and F. D. Rossini, J. Research NBS 46, 106 (1951) RP2181.

[12] J. R. Eckman and F. D. Rossini, BS J. Research 3, 597 (1929) RP111.

[13] E. Wichers, J. Am. Chem. Soc. 78, 3238 (1956).

[14] E. J. Prosen, Chapter 6 in Experimental thermochemistry, F. D. Rossini, ed. (Interscience Publishers, Inc., New York, N.Y., 1956).

[15] F. D. Rossini, D. D. Wagman, W. H. Evans, S. Levine, and I. Jaffe, Selected values of chemical thermodynamic properties, NBS Circ. 500 (U.S. Government Printing Office, Washington 25, D.C., 1952).

[16] W. H. Johnson, R. A. Nelson, and E. J. Prosen, J. Research NBS 62, 1 (1959), RP2928.

[17] F. R. Bichowsky and F. D. Rossini, Thermochemistry of the chemical substances (Reinhold Publishing Corp., New York, N.Y., 1936).

[18] K. K. Kelley, Contributions to the data on theoretical metallurgy, III. The free energies of vaporization and vapor pressures of inorganic substances, U.S. Bureau of Mines, Bull. 383, (U.S. Government Printing Office, Washington 25, D.C., 1935).

[19] M. Farber and A. J. Darnell, J. Chem. Phys. 25, 526 (1956).

[20] M. Farber and A. J. Darnell, J. Phys. Chem. 59, 156 (1955).

(Paper 64A6-74) 